\title{
A Model of Market Segmentation with Risk
}

\author{
Ori Marom \\ William E. Simon Graduate School \\ of Business Administration \\ University of Rochester, Rochester, NY 14627 \\ marom@simon.rochester.edu
}

\author{
Abraham Seidmann \\ William E. Simon Graduate School \\ of Business Administration \\ University of Rochester, Rochester, NY 14627 \\ seidmannav@simon.rochester.edu
}

\begin{abstract}
We characterize an optimal scheme for the sale of multiple items of a good by a monopolist in a market comprised of risk averse buyers. It is established that by randomizing prices in one channel while also offering a risk-free alternative in another a seller may obtain segmentation benefits. The optimal vehicle of such price randomization is a draw from a discrete two-points probability distribution function. We use the model to offer explanations for observed on-line sellers' behavior and discuss implementation issues in view of recent e-commerce environments.
\end{abstract}

\section{Introduction}

In internet based commerce, it is often observed that some sellers use (either separately or simultaneously) multiple distribution channels for the sale of standard consumer goods. For example, we found that within a two weeks period Carnival cruise lines has offered units of the same cabin class on one of its ships while using three distinct on-line selling methods: standard posted price, first price auction and 'last minute' clearance sale. A possible explanation for such behavior is that sellers such as Carnival are deliberately embedding price uncertainties into their sales channels in order to employ second degree price discrimination among buyers who are risk averse. Buyers who assign higher values to the offered product are typically more reluctant to risk compromising their surplus and are therefore prone towards an early 'risk free' purchase at a higher posted price while buyers with lower values may be willing to wait and attempt to acquire the product at a bargain price.

We begin the discussion by introducing a numerical example. A cruise line operator has 400 cabins left for sale on one of her ships. There are 1000 potential clients in the market whose values (v) for the cruise are uniformly and independently distributed between $\$ 0$ and $\$ 1000$. Suppose that buyers in this market are known to be highly risk averse; once they set their minds on a specific cruise and avail time away from work they would truly detest changing their plans due to unavailability. The seller accordingly estimates buyers' utility to be represented by the function $U=(v-p)^{1 / 4}$ where the term in the parentheses is net surplus from consumption of cruise vacations. In case of no purchase a buyer's utility is zero.

The setup is such that the cruise operator has exactly three possible selling methods: a posted price, a multi-unit online auction and a random 'last minute' sale event, held with probability of $\alpha$. The seller may use any combination of the three in designing a selling scheme and we assume that all buyers are kept fully informed regarding her choice.

For instance, the seller may choose to sell units for a posted price of $\$ 700$, auction off (with certainty) 15 units, and then offer any remaining unit at a clearance sale 14 days prior to departure, but only with probability of $\alpha=50 \%$ (so that with probability of $50 \%$ some capacity may remain unsold).

As the optimal solution, we would prescribe the following:

- Set the posted price at $\$ 658$ per cabin.

- Announce that with probability of $79 \%$ a 'last minute' sale will take place, in which units will be sold for $\$ 600$ each.

- Do not auction off units at any time.

In the resulting equilibrium 303 cabins are sold immediately and 97 cabins are reserved for the 'last minute' clearance sale. Consequently, the seller's revenues are $\$ 245,720$ or about $2.4 \%$ higher than what she could obtain otherwise by charging only a spot price of $\$ 600$ while selling all 400 available units with certainty. 


\subsection{Related literature}

The potential segmentation benefits which may arise from price randomization have long been recognized. Stiglitz [15] suggested that incentive schemes yielding random outcomes may be desirable when agents are risk averse but has not described optimal policies that involve such randomization. In contrast, Riley and Zeckhauser [14] have shown that when buyers are risk neutral and the seller has no capacity constraint a deterministic one-price scheme is always optimal. In two independent seminal studies, Matthews [11] and Maskin and Riley [10] have characterized optimal auctions with risk averse buyers under different sets of assumptions. While assuming, as we do in this paper, that buyers have uniform utility functions and differ only in their valuation of the good, both studies establish that the seller can devise a truth revelation mechanism that strictly dominates any oneprice scheme while inducing an equilibrium in which almost all buyers are faced with risk. Within such an 'optimal auction' every buyer is induced to reveal his value of the good; based on this report he is then assigned a schedule that includes a 'bid submission' fee, a probability of winning the item, and finally, an 'acquisition price' to be paid only if the item is won. Matthews established that in the particular case in which buyers exhibit constant absolute risk aversion (CARA) the acquisition price of any schedule should optimally be deterministic. Maskin and Riley deviated form this rather restrictive assumption at the cost of not obtaining necessary and sufficient conditions for the optimality of their suggested mechanism. Furthermore, it appears that the main barrier to the implementation of mechanisms resembling such 'optimal auctions' in real-world markets is their inherent complexity. In fact, to the best of our knowledge no such selling scheme was ever used.

Varian [16] explained price dispersions in markets in which multiple sellers compete for sales of a homogenous good. He argues that when buyers differ in their ability to access price information the optimal selling scheme involves price randomization as the unique symmetric equilibrium outcome. The motivation behind such randomization is the desirability for sellers to avoid head-on Bertrand competition. Baye and Morgan [2] extended this model to include a monopolistic electronic intermediary that facilitates the transmission of price information while charging participating sellers and buyers nominal access fees. Interestingly, they found that at the resulting equilibrium, sellers' decision to participate takes the shape of a random event with probability $\alpha$ while their advertised price is a random variable drawn from a continuous distribution $\mathrm{F}(\mathrm{p})$. While both aforementioned papers are closely related to our work, we consider a monopoly seller rather than a competitive environment and thus our paper entails an alternative exploration into the problem of characterizing optimal price randomization schemes.

In this paper, a simple two-period model of segmentation with random prices is constructed. We are assuming a specific utility function and only two possible available pricing schemes: a 'risk free' channel which consists of a single posted price, and a 'risky' channel in which price is a random variable drawn from a probability distribution. We do not impose any restrictions on the shape of this distribution. Within this framework, we are able to fully characterize the profit maximizing policy and investigate its behavior under different degrees of buyers' risk aversion and seller's available capacity levels. We show that when the sellers' available capacity is unlimited and buyers exhibit strict risk aversion the optimal instrument of price randomization is a discrete two-points distribution. In contrast, when buyers are risk neutral or when the seller's available capacity falls below a threshold which is a concave function of the degree of buyers relative risk aversion, it is found that the optimally policy is a one-price scheme. One feature of our model is that it allows for a compact parametric representation of the uncertainty faced by buyers in equilibrium. We find that the optimal level of price uncertainty is a monotonically decreasing function of buyers' degree of risk aversion. Optimal pricing policies will also be discussed. While the optimal 'risk free' posted price is found to be monotonically increasing with respect to the degree of buyers' risk aversion, the average price in the 'risky' channel is monotonically decreasing with respect to it. In addition, it will shown that the seller's optimal response to any incremental increase in buyers' risk aversion is to increase in the new equilibrium the proportion of the available capacity sold (on average) at the 'risky' channel.

The remainder of the paper is organized as follows. In Section $\$ 2$ we begin by constructing a model without a capacity constraint. This is followed by an analysis of the resulting equilibrium (theorems 1 and 2). In section $\S 3$ we add a capacity constraint to the basic model and discuss this more general case (theorem 3 ). In section $\S 4$ we bring forth some welfare implications of the model. Section $\S 5$ includes a discussion of a number of relevant implementation issues in view of recent IT enabled markets.

\section{Model}

We consider the problem of a risk neutral seller who wishes to maximize her expected revenue from the sale of a good. The seller is a monopolist in the market and we normalize her constant marginal cost of production to be zero. For this part of the analysis, we 
also assume that the seller's production capacity is unlimited. The model consists of two periods. In the first period, the seller offers the good for sale at some posted per-unit price we denote by $\mathrm{p}_{1}$; whereas in the second period, the price $\mathrm{p}_{2}$ is a random draw from a discrete probability distribution $\mathrm{f}(\mathrm{x}, \mathrm{a})$. The term $x=\left\{x_{i}\right\}_{i=1}^{n}$ is a vector of $\mathrm{n}$ non-negative prices which are indexed in an increasing order $\left\{i<j \rightarrow x_{i} \leq x_{j}\right\}$, and $a=\left\{\alpha_{i}\right\}_{i=1}^{n}$ is a vector of $\mathrm{n}$ probabilities such that $\operatorname{Pr}\left[p_{2}=x_{i}\right]=\alpha_{i}$ for all $\{\mathrm{i}=1,2, . ., \mathrm{n}\}$, and $\sum_{i=1}^{n} \alpha_{i} \leq 1$.

Using the above terms, we let the vector $S=\left\{p_{1}, x, a\right\}$ represent the seller's 'pricing policy'. The seller announces the policy $S$ at the beginning of the first period of the model and we assume that she can credibly commit to truthfully following it. The discussion of issues that are related to this assumption is intentionally left outside the scope of this paper, for the sake of brevity.

- Remark: although we consider only discrete price distributions, any interesting continuous distribution may be approximated by a discrete form and hence no generality is lost.

The market is comprised of a large number of buyers whose values for the good are independently and uniformly distributed over a unit interval $v_{i} \sim U[0,1]$ and each buyer's demand is for a single unit of the good. Buyers are risk averse and their preferences uniformly represented by the utility function $u\left(v_{i}, p\right)=\left(v_{i}-p\right)^{1-\rho}$. The parameter $\rho$ is common to all buyers and may range between 0 and 1 , this term is often referred to in related literature as the degree of buyers' relative risk aversion.

The dynamics of the model are described as follows. At the beginning of the first period, all buyers freely observe the policy S. Each buyer then individually chooses whether to purchase the good at a price of $p_{1}$ or delay his decision until the next period. At the second period, the realization of the random variable $\mathrm{p}_{2}$ becomes known and all buyers whose values exceed this price make their purchases. At the same time, buyers with values lower than $\mathrm{p}_{2}$ end up with no purchase and with a utility of zero.

\subsection{Buyers' Behavior}

A buyer with value is $\mathrm{v}$ will optimally purchase the good at the first period if and only if the following two conditions are met

$$
\begin{aligned}
& \text { (1) } \quad \mathrm{v} \geq \mathrm{p}_{1} \\
& \text { (2) } \Delta(\mathrm{v})=\left(\mathrm{v}-\mathrm{p}_{1}\right)^{1-\rho}-\sum_{i=1}^{m(v)} \alpha_{i}\left(v-x_{i}\right)^{1-\rho} \geq 0
\end{aligned}
$$

Where $m(v)$ is the index of the highest price not exceeding $\mathrm{v}$. The function $\Delta(\mathrm{v})$ represents a buyer's excess utility from a risk free purchase. It can be shown that $\Delta(\mathrm{v})$ is everywhere continuous with respect to buyers' value but is not always monotone with respect to it. The following lemma offers an important necessary condition for random-price channel participation

Lemma 1: A buyer will delay his purchase at the first period only if he expects an (average) price discount to materialize at the second period: $\Delta(\mathrm{v}) \leq 0 \Rightarrow \mathrm{p}_{1} \geq \sum_{\mathrm{i}=1}^{\mathrm{m}(\mathrm{v})} \alpha_{\mathrm{i}} \mathrm{x}_{1} \quad$,all $\mathrm{v} \in\left[\mathrm{p}_{1}, 1\right]$

All proofs in this paper are contained in the Appendix. Lemma 1 seems very intuitive. We learn from it that even though positive probabilities may be assigned to second period prices that are higher than the first period posted price $\left(\mathrm{p}_{1}\right)$, the average revenue generated to the seller by any second period buyer would always be lower than that of a first period buyer.

We dedicate the next sub-section to the study of the family of policies that include a two points price distribution at the second stage $(\mathrm{n}=2)$. Furthermore, we shall restrict one of those prices to be sufficiently high so that no buyer would be willing to transact at it. This form is of special importance as it will be shown at the next section that the seller can always find an optimal policy which belongs to it.

- Market Equilibria with 'Two-Price' Policies: For added clarity, we repeat in plain words the market scenario of this case. In the first period, the seller posts a 'spot' price of $\mathrm{p}_{1}$ and announces that with probability of $\alpha$ she will hold a random 'sale' event in the second period, and that the 'sale' price will be $\mathrm{p}_{2}$. However, if a 'sale' is eventually not held, the seller will refuse selling the product in the second period altogether.

In our previous notations, the above takes the form of the following policy

$$
S=\left\{p_{1}, x, a\right\}, x=\left\{p_{2}, h\right\}, a=\{\alpha, 1-\alpha\}
$$

Where $h$ is any number strictly greater than 1, which is the highest possible value a buyer may assume in our model. Throughout the paper we shall use the convention $h=\infty$. In the particular case of the above policy S, it can be shown that buyers' excess utility from risk free purchase $\Delta(v)$ is a monotonically increasing function with respect to $\mathrm{v}$ for any parameter value and therefore has, at most, a single crossing at a level of 
zero. This threshold value may therefore assume a functional form. This is given by

$$
b=b\left(p_{1,} p_{2,}, \alpha, \rho\right)=\operatorname{Min}\left(\frac{p_{1}-\alpha^{1 /(1-\rho)} p_{2}}{1-\alpha^{1 /(1-\rho)}}, 1\right)
$$

All buyers with values higher than $b$ optimally make their purchases in the first period whereas all buyers with values between $p_{2}$ and $b$ make purchases at the second period whenever a 'sale' is held. Quite expectedly, the function $\mathrm{b}$ is found to be monotonically increasing with respect to both $\mathrm{p}_{1}$ and $\alpha$, and monotonically decreasing with respect to both $\mathrm{p}_{2}$, and $\rho$.

\subsection{Firm's behavior and the characterization of a profit maximizing policy}

The seller's aim is to select a policy in order to maximize her expected profits while assuming that all buyers are kept fully informed and behave rationally. Without any loss of generality, we restrict our attention to the domain $\Theta(\rho)$ of policies which induce a partition of buyers into first and second demand sets that are contiguous and touching at a single point $b(S, \rho)$. This restriction requires that if a buyer prefers to make his purchase in the first period then so will all buyers with values higher than his.

To save on notations we use simply $\Theta$ and $b$. With that, the seller's optimization problem takes the form

$$
\underset{S \in \Theta}{\operatorname{Max}} \quad p_{1}(1-b)+\sum_{i=1}^{m(b)} \alpha_{i}\left(b-x_{i}\right) x_{i}
$$

Before proceeding to the solution, we provide a simple example in order to illustrate the considerations involved in the seller's selection of a policy. For this example, suppose that the seller compares only the following two policy alternatives:

$$
\mathrm{S}_{1}=\{1 / 2,\{\varnothing\},\{\varnothing\}\} \quad \mathrm{S}_{2}=\{2 / 3,\{1 / 3, \infty\},\{1 / 2,1 / 2\}\}
$$

We shall refer to $S_{1}$ as 'the benchmark policy'. This is the optimal one-price policy by which the seller may turn a profit of $1 / 4$ simply by charging a fixed price of $1 / 2$ in a single period. We now turn to calculate demand under the policy $\mathrm{S}_{2}$. Because we assume that buyers value are uniformly distributed, the proportion of buyers who makes purchases in the first period after observing the policy $S_{2}$ is given by (1-b) where $b$ is described by equation (3); the second period demand is similarly given by $1 / 2 \cdot(b-1 / 3)$ and the overall profit from this strategy is given by

$$
\Pi\left(S_{2}\right)=\frac{5 \cdot 2^{1 /(1-\rho)}-8}{18 \cdot\left(2^{1 /(1-\rho)}-1\right)}
$$

The above profit function is monotonically increasing with respect to the degree of buyers' relative risk aversion and exceeds the benchmark profit if and only if $\rho$ is greater than 0.644 . Figure 1 assists us in describing the different effects which come into play in the comparison between the alternative equilibria under the policies $S_{1}$ and $S_{2}$. In segment $I$ better surplus extraction is attained by using the policy $\mathrm{S}_{2}$, at the same time, the seller loses revenues from buyers whose values fall within in segment II due to a cannibalization (or leakage) effect; whereas in segment III the seller benefits from extending her market to newly include lower valued buyers. The key question is whether (and under what circumstances) the seller may find a policy which would generate an overall increase in profits as the sum result of all three effects.

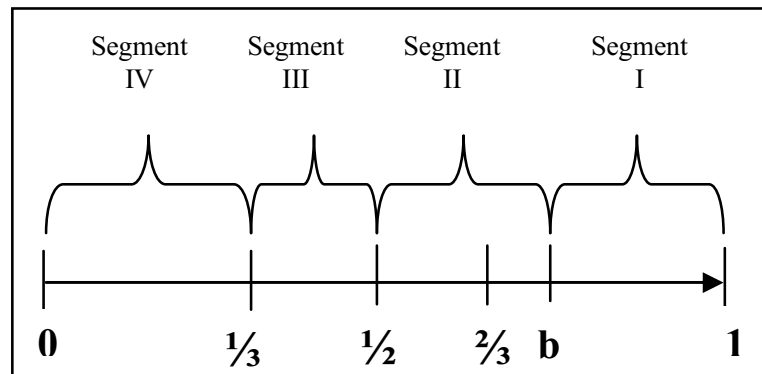

Figure 1. Market segmentation (example)

Our first theorem asserts that when buyers are risk neutral the seller can not attain a profitable segmentation.

Theorem 1: Let buyers be uniformly risk neutral $(\rho=0)$ and let $\hat{S}=\left(\hat{p_{1}}, \hat{x}, \hat{\alpha}\right)$ be a policy that induces a non-empty subset of buyers to make purchases in the first period. Then,

$$
\Pi(\hat{S}) \leq \hat{p}_{1}\left(1-\hat{p}_{1}\right)
$$

Surprisingly, we find that the fact that introducing a random second period price is never optimal does not depend on the optimality of the first period price in a policy. Our next task is to show how buyers' risk aversion may change the nature of the seller's solution. Intuitively, a sufficiently high degree of buyers' risk aversion might mitigate the negative effects of cannibalization to an extent that would enable the seller to exploit price uncertainty in order to increase her profit. In fact, we found that for any degree of risk aversion the seller may indeed find a two prices policy that is strictly better than the fixed price benchmark. We now turn to formalize the main result of this paper. 
Theorem 2: $\quad$ For any degree of strict risk aversion $\{0<\rho<1\}$ there exists a profit maximizing policy $S^{*}(\rho)=\left\{p_{1}^{*}(\rho), x^{*}(\rho), a^{*}(\rho)\right\}$ that involves two distinct second period prices $x^{*}(\rho)=\left\{p_{2}(\rho), \infty\right\}$ to be charged with two corresponding strictly positive probabilities $a^{*}(\rho)=\{\alpha(\rho), 1-\alpha(\rho)\}$. This optimal policy strictly dominates any one-price scheme $\left\{\Pi\left(S^{*}\right)>1 / 4\right\}$.

A central implication of theorem 2 is that the optimal vehicle of price randomization within a two channel structure is a draw from a discrete two-points probability distribution function where one of the points represents a price that is prohibitively high. We could not, however, find a strong economic intuition behind this result.

\subsection{Comparative Statics}

In this section we describe the effects of changes in the degree of buyers' risk aversion on various equilibrium variables of the model. From the appendix, the two prices of profit maximizing policy are formulated by equations (5) and (6):

$$
\begin{aligned}
& p_{1}^{*}=\frac{2\left(1-\left(\alpha^{*}\right)^{1 /(1-\rho)}\right)}{4-\alpha\left(1+\left(\alpha^{*}\right)^{\rho /(1-\rho)}\right)^{2}} \\
& p_{2}^{*}=\frac{\left(1-\left(\alpha^{*}\right)^{1 /(1-\rho)}\right)\left(1+\left(\alpha^{*}\right)^{\rho /(1-\rho)}\right)}{4-\alpha\left(1+\left(\alpha^{*}\right)^{\rho /(1-\rho)}\right)^{2}}
\end{aligned}
$$

Where the probability $\alpha^{*}$ is determined as the unique feasible solution to the equation

$$
\begin{aligned}
& \left(\alpha^{(1+\rho) /(1-\rho)}+\alpha^{(1 /(1-\rho))}\right)\left(\frac{\rho}{1-\rho}\right) \\
& -\alpha^{\rho /(1-\rho)}\left(\frac{1+\rho}{1-\rho}\right)+1=0
\end{aligned}
$$

We use the above derivations in order to investigate the relationships between buyers' risk aversion and the seller's optimal policy variables (see Figures $2 \mathrm{~A}$ and 2B), and attempt to explain their meanings.

It is an intuitive result that the first period price is found to be strictly increasing with risk aversion (see figure 2A); the increased reluctance on the part of buyers to incur price uncertainty intensifies the demand for purchases in the first period and results in a correspondingly higher posted price $\left(\mathrm{p}_{1} *\right)$. At the same time, the optimal 'sale' price $\left(\mathrm{p}_{2}{ }^{*}\right)$ of the second period is a decreasing function of buyers' risk aversion since a reduced cannibalization effect allows the seller to charge a price which is closer to the ex-post efficient level given by $b\left(S^{*}\right) / 2$ (this is the price that the seller would charge at the second period if she were to defect from truthfully following her declared policy). Interestingly, the optimal probability of a 'sale' $\left(\alpha^{*}\right)$ is found to be monotonically increasing with risk aversion (see figure 2B). In other words, in environments where buyers would be more reluctant to incur transaction risk the model advocates installing mechanisms which assign higher probabilities to lower prices. Still, as figure 2C shows, with increased risk aversion it is observed that a ratio of average sales in the two periods always tilts in favor of the second period channel (!). Lastly, it is an obvious result that the monopoly's payoff increases monotonically with risk aversion (see figure 2D). This phenomenon is a direct consequence of the monopoly's enhanced capacity to segment its market.

\subsection{Third party re-sellers}

In the preceding analysis we assumed that the seller is not only the monopoly producer of the good but also the only risk neutral agent in the market. We now consider an alternative case in which an arbitrary number of risk neutral re-sellers also exist in the market. The re-sellers are not authorized by the wholesaler and are therefore compelled to buy the good at a forward retail price in hope to sell it later at a profit once its value appreciates. We assume that no re-seller derives any direct utility from consumption of the good. From the buyers' perspective, we ignore some implications, such as lack of warranty, and assume that all buyers are indifferent between buying from the monopoly producer and buying from a re-seller. The question we then ask is whether or not it would be possible for any number of re-sellers to turn arbitrage profits in the market. It turns out that the answer to this question is negative, as we show next.

In case a sale does not take place by the producer in the second period, let us assume that all re-sellers charge the price $\psi$ in a symmetric equilibrium. Each re-seller's expected (per-unit) profit is then given by

$$
\Pi_{r s}(\psi)=(1-\alpha) \psi+\alpha p_{2}-p_{1}
$$

Therefore, the minimal equilibrium price $\psi$ which would result in a non-negative profit for a re-seller is

$$
\psi_{\min }=\frac{p_{1}-\alpha p_{2}}{1-\alpha}
$$

However, since the utility function of buyers is concave, it is straightforward to verify that no buyer would be willing to buy at this price. Indeed, by the definition of strict concavity we get

(10) $\alpha\left(v-p_{2}\right)^{1-\rho}+(1-\alpha)\left(v-\psi_{\min }\right)^{1-\rho}<\left(v-p_{1}\right)^{1-\rho}$

We conclude that the monopoly's capacity to profitably segment the market with risk may not be impaired by the presence of risk neutral re-sellers. 

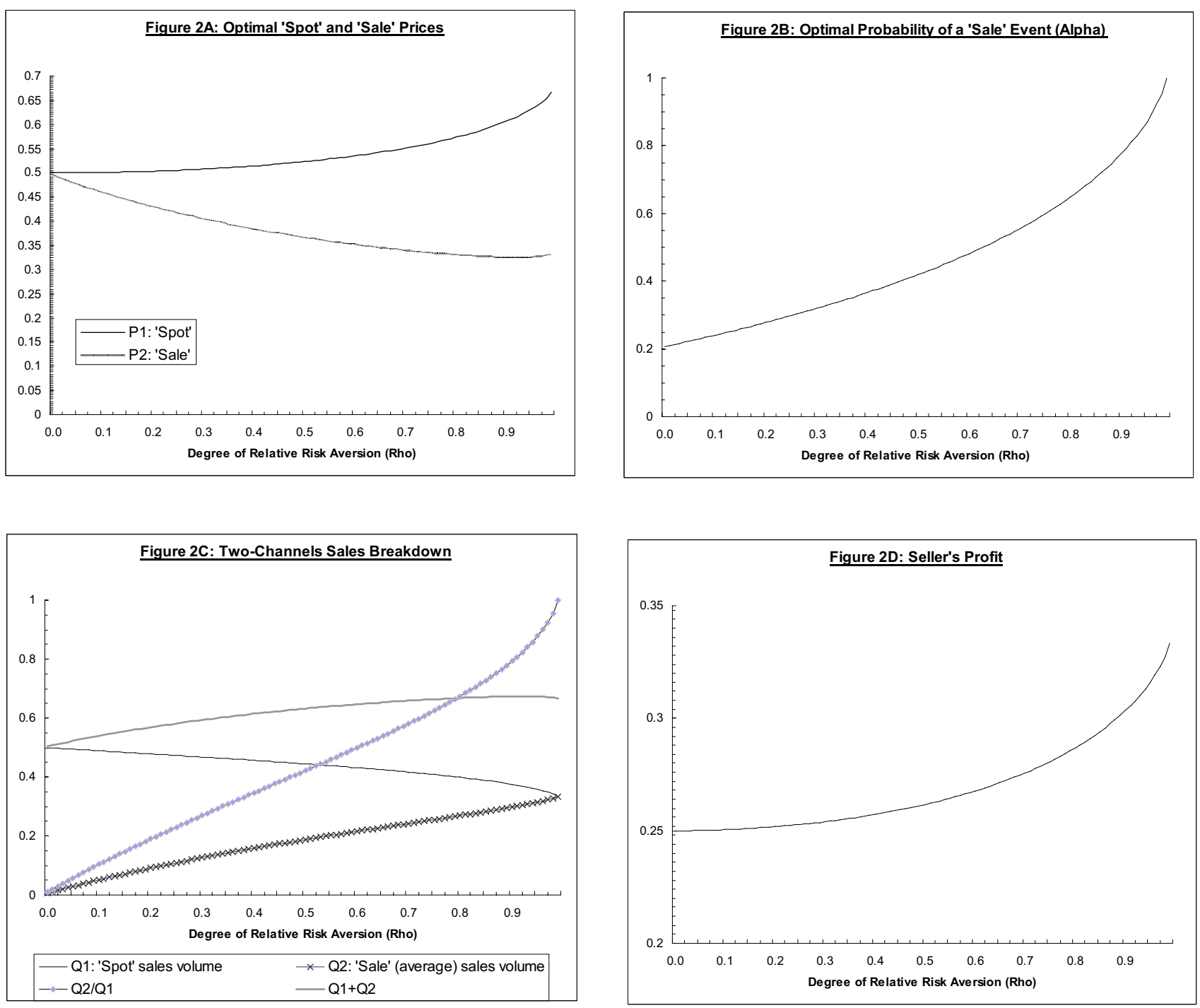

Figures 2(A)- (D). Uncapacitated model behavior

\section{Limited capacity}

In this section, we incorporate a capacity constraint into the model and analyze the resulting equilibrium. The most important point we will show is that when merchandize is in short supply relative to demand, the seller should optimally charge only one price.

For this part, we assume that buyers freely observe the seller's available production capacity (denoted $\mathrm{k}$ ) at the first period of the model. The entire lot is readily available for sale at the first period and any unsold unit can be costlessly carried over by the seller to the second period. In order to be brief, we do not model 'stock outs'; that is, we assume that within any chosen policy the seller does not assign positive probabilities to scenarios in which demand exceeds supply. Hence, the minimal price that may be charged at any equilibrium is (1-k). With that, we present the following result
Theorem 3: $\quad$ Let $\rho$ be the degree of buyers' relative risk aversion $\{0 \leq \rho<1\}$ and let $k$ be the overall (two period) seller's available capacity $\{0 \leq k \leq 1\}$. Then, there exists a profit maximizing policy $S^{*}(\rho, k)=\left\{p_{1}^{*}(\rho, k), x^{*}(\rho, k), a^{*}(\rho, k)\right\}$ that involves two second period prices $x^{*}(\rho, k)=\left\{p_{2}^{*}(\rho, k), \infty\right\}$ and two corresponding probabilities $a^{*}(\rho)=\left\{\alpha^{*}(\rho, k), 1-\alpha^{*}(\rho, k)\right\}$ and strictly dominates any one-price charge, if and only if buyers are risk averse $(\rho>0)$ and the seller's capacity exceeds a concave threshold function: $k>\frac{1-\rho}{2-\rho}$.

The proof of theorem 3 is available upon request. When production capacity is limited the seller targets buyers 
with higher values for the good and has a lesser or no incentive to use segmentation tools in order to include buyers with relatively low values. In addition, the opportunity cost of unsold capacity in realizations in which the second period price turns up to be 'high', is more significant. We find that both effects results in optimal channeling of a smaller proportion of available capacity to the second period, or even the elimination of second period sales in scenarios with very low capacity level.

\section{Welfare implications}

The following contains a brief discussion of the welfare implications of the model. Assuming the stand point of a social planner, we define total welfare as the aggregation of net expected consumer surplus and the seller's equilibrium profit: $W=C S+\Pi$; Under the optimal two price policy of either the capacitated or the uncapacitated cases we have

$$
\begin{aligned}
& C S=\frac{\left(1-p_{1}\right)^{2}-(1-\alpha)\left(b-p_{2}\right)^{2}}{2} \\
& \Pi=\left(1-p_{1}\right) p_{1}+\alpha\left(b-p_{2}\right) p_{2}
\end{aligned}
$$

By analyzing the equilibrium values of the above parameters, we find that regardless of risk aversion and available capacity levels consumers are always worse off at the aggregate as compared to a one price monopoly scenario. This result holds in an even stronger sense because at the above we ignored buyers' disutility from bearing risk. When available capacity is unlimited the total social welfare always increases as a result of increased production. In cases where the capacity constraint is binding in equilibrium, however, this result becomes ambiguous. Social welfare may decrease.

\section{Conclusions and IT perspectives}

In this paper we established the following: (1) firms with monopoly power can segment markets while using relatively simple schemes that involve price randomization. (2) In implementing such policies firms should monitor available sales capacity levels and assess buyers' attitudes towards risk, and then design the profit maximizing schemes accordingly.

A number of open questions remain: (1) Could firms with less than full degree of monopoly power utilize such strategies? (2) What would be the effects of positive transaction, search and venue costs? (3) What could be the effects of non linear cost functions?

In view of practical implementation issues which are related to our model we regard IT enabled markets as playing a central role. Indeed, the internet has facilitated new and more elaborate selling methods, such as multi-unit auctions (see Pinker et al. [13]). Moreover, it allows sellers to offer items on multiple web channels at the same time without incurring large incremental costs, such as inventory holding costs, per each featured channel. Also, new technologies of on-line inventory and customer data management systems allow the sellers new capabilities to dynamically set their prices over time in order to maximize profits (see Choudhary et al. [4]).

The internet had reduced buyers search costs significantly (for a discussion see Bakos [1]) and new questions arise as to the impact that this may have on sellers' profitability and competitiveness. Brynjolfsson and Smith [3] and Clemons et al. [5] argue that in both commodity and differentiated product e-markets significant price dispersions are found. Those papers provide evidence that sellers who use the internet do not necessarily turn to compete on price alone and that many buyers are willing to pay a premium in order to purchase a good on-line from a seller of their choice. In this paper we provide an argument for the case that the reduction in buyers' search costs may actually increase sellers' segmentation benefits by allowing them to position items on multiple channels while facilitating buyers choice as to the price/product selling scheme that fits them best.

\section{References}

[1] Bakos, J.Y., "Reducing Buyer Search Costs: Implications for Electronic Marketplaces", Management Science, Vol. 43(12), 1997, 1613-1630.

[2] Baye, M.R., Morgan, J.,"Information Gatekeepers on the Internet and the Competitiveness of Homogeneous Product Markets", American Economic Review, June 2001, 454-474.

[3] Brynjolfsson, E, Smith, M.D., "Frictionless Commerce? A Comparison of Internet and Conventional Retailers", Management Science 46(4), April 2000, 563-585

[4] Choudhary, V., Aninda, G., Mukhopadhyay, T., Rajan, U., "Personalized Pricing and Quality Differentiation on the Internet”, Working Paper (2002), GSIA, Carnegie Mellon University.

[5] Clemons, E.K., Hann, I.H.,Hitt, L.M., "Price Dispersion and Differentiation in Online Travel: An Empirical Investigation" ", Management Science, Vol. 48(4), April 2002, 534-549.

[6] Deneckere, R.J. and McAfee, R.P., "Damaged Goods", Journal of Economics \& Management Strategy, volume 5, number 2, 1996, 149-174.

[7] Etzion, H., Pinker E., Seidmann A., "Analyzing the Simultaneous Use of Auctions and Posted Prices for On-line Selling”, Working Paper (2003), Simon School, University of Rochester. 
[8] Gerstner, E. and Holthausen D.: "Profitable Pricing When Market Segments Overlap”, Marketing Science 5 v.1 (1986), pp. 55-69

[9] Marom, O., Seidmann A.,"Market Segmentation with Risk and the Use of Online Auctions", Working Paper (2003), Simon School, University of Rochester.

[10] Maskin, E. and Riley,J., "Optimal Auctions With Risk Averse Buyers" Econometrica, Volume 52, Issue 6 (Nov., 1984), pp. 1473-1518.

[11] Matthews, S.A., "Selling to Risk Averse Buyers with Unobservable Tastes", Journal of Economic Theory, Vol. 30 (1983), 370-400.

[12] Mussa. M.S., Rosen, S., "Monopoly and Product Quality", Journal of Economic Theory 18 (1978), 301-317.

[13] Pinker, E. J., Seidmann, A. and Vakrat, Y.:,“The Design of Online Auctions: Business Issues and Current Research", Management Science, Vol. 49(11),2003

[14] Riley, J., Zeckhauser, R., "Optimal Selling Strategies: When to Haggle, When to Hold Firm", The Quarterly Journal of Economics, Vol. 98, No. 2(May 1983), 267-289.

[15] Stiglitz, J. E.: "Self-selection and Pareto Efficient Taxation”, Journal of Public Economics, Vol. 12 (1982), 213240.

[16] Varian, H.,"A Model of Sales", American Economic Review, September 1980, 70(4), 651-659.

\section{Appendix I: Proofs}

Lemma 1: The utility function is concave and monotonically increasing with respect to value. Therefore, $\Delta(\mathrm{v})<0$ implies

$$
\begin{aligned}
& 0>\left(\mathrm{v}-\mathrm{p}_{1}\right)^{1-\rho}-\sum_{i=1}^{m(v)} \alpha_{i}\left(v-x_{i}\right)^{1-\rho} \geq\left(\mathrm{v}-\mathrm{p}_{1}\right)^{1-\rho} \\
& \left.-\left(\sum_{i=1}^{m(v)} \alpha_{i}\left(v-x_{i}\right)\right)^{1-\rho} \geq\left(\mathrm{v}-\mathrm{p}_{1}\right)^{1-\rho}-\left(v-\sum_{i=1}^{m(v)} \alpha_{i} x_{i}\right)\right)^{1-\rho} \\
& \rightarrow \mathrm{p}_{1}>\sum_{i=1}^{m(v)} \alpha_{i} x_{i}
\end{aligned}
$$

Theorem 1: The set of equilibrium first period buyers is non-empty. If the set of equilibrium second period buyers is empty then () is trivially satisfied and we are done. Let us assume then that the second period buyers' set is non-empty. When $\rho=0$, the function $\Delta(v)$ given in equation (2) is a continuous and monotonically increasing function and its domain is a closed interval. Hence, by the mean value theorem there exists a unique value $b \in(0,1)$ such that $\Delta(b)=0$. The seller's profit function when buyers are risk neutral is given by

$$
\Pi(\hat{S})=\hat{p}_{1}(1-b)+\sum_{i=1}^{m(b)} \hat{\alpha}_{i}\left(b-\hat{x_{i}}\right) \hat{p_{1}}
$$

By the incentive constraint of the indifferent buyer (2) we obtain

$$
\hat{p_{1}}=\left(1-\sum_{i=1}^{m(b)} \hat{\alpha_{i}}\right) b+\sum_{i=1}^{m(b)} \hat{\alpha_{i}} \hat{x_{1}}
$$

For notational convenience we denote $F(b) \equiv \sum_{i=1}^{m(b)} \hat{\alpha}_{i}$ and, with this term, we define the following revenue equivalent policy $\bar{S}$ to be:

$$
\begin{aligned}
& \bar{S}=\left\{\hat{p_{1}}, \bar{x}, \bar{\alpha}\right\} ; \quad \bar{x}=\left\{\hat{x}_{1}, \hat{x}_{2}, \ldots, \hat{x}_{m(b)}, b\right\}, \\
& \bar{\alpha}=\left\{\hat{\alpha}_{1}, \hat{\alpha}_{2}, \ldots, \hat{\alpha}_{m(b)}, 1-F(b)\right\}
\end{aligned}
$$

It is easy to see that $\Pi(\bar{S})=\Pi(S)$. We will show that the variance of the second period price, within the equilibrium induced by the optimal policy, must be zero. The required variance term is formulated by

$$
\begin{gathered}
\sigma^{2} \equiv E_{\bar{\alpha}}\left(\bar{x}_{i}-\hat{p}_{1}\right)^{2}=(1-F(b))\left(b-\hat{p_{1}}\right)^{2} \\
+\sum_{i=1}^{m(b)} \bar{\alpha}_{i}\left(\bar{x}_{i}-\hat{p}_{1}\right)^{2}=(1-F(b)) b^{2}-p_{1}{ }^{2}+\sum_{i=1}^{m(b)} \bar{\alpha}_{i}\left(\bar{x}_{i}\right)^{2}
\end{gathered}
$$

Equations (9) and (10) yield the following expressions, respectively

$$
\begin{aligned}
& \sum_{i=1}^{m(b)} \bar{\alpha}_{i} \bar{x}_{i}=\hat{p_{1}}-(1-F(b)) b \\
& \sum_{i=1}^{m(b)} \bar{\alpha}_{i}\left(\bar{x}_{i}\right)^{2}=\bar{\sigma}^{2}+\hat{p}_{1}{ }^{2}-(1-F(b)) b^{2}
\end{aligned}
$$

Once we incorporate the expressions for the left hand side terms in (11) and (12) into the profit function (8) we finally get our required result: $\Pi(\hat{S})=\left(1-\hat{p_{1}}\right) \hat{p_{1}}-\sigma^{2}$. From the non-negativity of the above variance term we know that the policy $\hat{S}$ is dominated by a policy where only one price $p_{1}$ is charged and our proof is thus complete. Note that we proved more than the theorem asserted: not only does the seller optimal policy consists of a single fixed price but also the profit function is monotonically decreasing in the second price variability $\left(\sigma^{2}\right)$. 
Theorem 2: We will first show that for any $\rho>0$ there exists a two price policy that yields $\Pi>1 / 4$ and will then argue that there exist no n-price policy that strictly dominates it. Let $S=\left\{p_{1}, x, a\right\}, \quad x=\left\{p_{2}, \infty\right\}$, $a=\{\alpha, 1-\alpha\}$ be a two price policy. It can be easily shown that this policy may induce, at most, a single threshold value in the market. This value is given by

$b\left(p_{1,} p_{2}, \alpha\right)=\frac{p_{1}-\alpha^{1 /(1-\rho)} p_{2}}{1-\alpha^{1 /(1-\rho)}}$

With the restriction that $\mathrm{b}$ must lie between $\mathrm{p}_{1}$ and 1 , the seller's problem becomes

$$
\begin{aligned}
& \operatorname{Max}_{\mathrm{p}_{1}, \mathrm{p}_{2}, \alpha} p_{1}\left(1-\frac{p_{1}-\alpha^{1 /(1-\rho)} p_{2}}{1-\alpha^{1 /(1-\rho)}}\right) \\
& +\alpha p_{2}\left(\frac{p_{1}-\alpha^{1 /(1-\rho)} p_{2}}{1-\alpha^{1 /(1-\rho)}}-p_{2}\right)
\end{aligned}
$$

s.t.:

(13.1) $p_{1} \geq p_{2}$

(13.2) $p_{1} \leq 1-\alpha^{1 /(1-\rho)}\left(1-p_{2}\right)$

(13.3) $0 \leq p_{1}, p_{2} \leq 1$

(13.4) $0 \leq \alpha \leq 1$

Fortunately, we found that whenever $\rho>0$ none of above listed constraints may bind at any optimum and we therefore ignore them in what follows.

- First order necessary conditions:

$$
\begin{aligned}
& \frac{\partial \Pi(\cdot)}{\partial p_{1}}=\frac{1}{1-\alpha^{1 /(1-\rho)}}\left(1-2 p_{1}+p_{2}\left(\alpha+\alpha^{1 /(1-\rho)}\right)\right. \\
& \left.-\alpha^{1 /(1-\rho)}\right)=0
\end{aligned}
$$

$$
\begin{aligned}
& \frac{\partial \Pi(\cdot)}{\partial p_{2}}=\frac{1}{1-\alpha^{1 /(1-\rho)}}\left(p_{1}\left(\alpha+\alpha^{1 /(1-\rho)}\right)-2 p_{2} \alpha\right)=0 \\
& \frac{\partial \Pi(\cdot)}{\partial \alpha}=\frac{p_{1}-p_{2}}{\alpha\left(1-\alpha^{1 /(1-\rho)}\right)^{2}(1-\rho)}\left(p_{1} \alpha^{1 /(1-\rho)}-p_{2}(\alpha(1-\rho)\right. \\
& \left.\left.+\rho \alpha^{(2-\rho)(1-\rho)}\right)\right)=0
\end{aligned}
$$

We assume for a moment that $\alpha<1$ and get by (14) and

$$
\begin{aligned}
& p_{1}^{*}=\frac{2\left(1-\alpha^{1 /(1-\rho)}\right)}{4-\alpha\left(1+\alpha^{\rho /(1-\rho)}\right)^{2}} \\
& p_{2}^{*}=\frac{\left(1-\alpha^{1 /(1-\rho)}\right)\left(1+\alpha^{\rho /(1-\rho)}\right)}{4-\alpha\left(1+\alpha^{\rho /(1-\rho)}\right)^{2}}
\end{aligned}
$$

From (16), (17) and (18) we derive the following condition for the term $\alpha$

$$
\begin{aligned}
& \left(\alpha^{(1+\rho) /(1-\rho)}+\alpha^{(1 /(1-\rho))}\right)\left(\frac{\rho}{1-\rho}\right)-\alpha^{\rho /(1-\rho)}\left(\frac{1+\rho}{1-\rho}\right) \\
& +1=0
\end{aligned}
$$

Equation (19) does not have a closed form solution and we used numerical methods to solve for $\alpha^{*}$. Note that by equations (17) and (18) the entire optimal policy is uniquely determined by this value. Still, it is to be verified that the numerical solution is indeed a global maximizer. We obtain the representation of profits under the hypothetical case where $\alpha$ is treated as a parameter

$$
\Pi^{*}(\alpha)=\frac{\left(1-\alpha^{1 /(1-\rho)}\right)}{4-\alpha\left(1+\alpha^{\rho /(1-\rho)}\right)^{2}}
$$

It can be checked that the above is a continuous and strictly concave function. Hence, the policy we found consists a global solution to the seller's problem, as required. Since it holds that $\operatorname{Lim}_{\alpha \rightarrow 0} \Pi^{*}(\alpha)=\operatorname{Lim}_{\alpha \rightarrow 1} \Pi^{*}(\alpha)=1 / 4$ the profit function is unimodal over its entire support $[0,1]$ and its mode is always found at an interior point of the support $(1>\alpha>0)$. The theorem's assertion that $\Pi^{*}(\alpha)>1 / 4$ for every $\rho>0$ is thus proven. It remains to be verified that there does not exist another policy $S_{n}$ which includes an n point second period price distribution $(n>2)$ and yields the seller a (strictly) higher payoff than does the optimal two points distribution we analyzed above. We let:

$$
\begin{aligned}
& S_{n}=\left\{p_{1}^{(n)}, F\left(x^{(n)}, a^{(n)}\right)\right\}, \quad x^{(n)}=\left\{x_{i}\right\}_{i=1}^{n}, \\
& a^{(n)}=\left\{\alpha_{i}\right\}_{i=1}^{n}, n>2
\end{aligned}
$$

Let us assume the contrary; that is, $S_{n}$ is the profit maximizing policy. Unlike a policy with a two-points distribution, the policy $S_{n}$ with $\mathrm{n}>2$ may result in more than one indifference point b. We pick, $\underline{b}=\operatorname{Min}_{v}\{v \mid \Delta(v)=0\}$ and use the consequence of Lemma 1 to derive an upper bound for profit

$$
\Pi\left(S_{n}\right) \leq(1-\underline{b}) p_{1}+\sum_{i=1}^{m(b)} \alpha_{i}\left(\underline{b}-x_{i}\right) x_{i}=\bar{\Pi}\left(S_{n}\right)
$$

Let us suppose for a moment that the seller, while making her policy decision, optimistically assumes that her payoff will be $\bar{\Pi}\left(S_{n}\right)$. Since $S_{n}$ is supposed to maximize the seller's payoff, it must in particular, dominate any policy $\mathrm{S}$ such that $p_{1}=p_{1}^{(n)}$ and 
$\underline{b}(S)=\underline{b}\left(S_{n}\right)$. Therefore, we fix $\underline{b}=\underline{b}\left(S_{n}\right)$ and $p_{1}=p_{1}^{(n)}$ as exogenous parameters and require the distribution variables $\{\mathrm{x}, \mathrm{a}\}$ which belong to $S_{n}$ to satisfy the first order KKT optimality conditions of the following problem

$$
\begin{aligned}
& \underset{\left\{x_{i}\right\}_{i=1}^{m(b)},\left\{\alpha_{i}\right\}_{i=1}^{m(b)}}{\max } \sum_{i=1}^{m(b)} \alpha_{i}\left(\underline{b}-x_{i}\right) x_{i} \\
& \text { s.t.: } \\
& \lambda_{0}: \quad 1-\sum_{i=1}^{m(\underline{b})} \alpha_{i} \geq 0 \\
& \lambda_{1}: \quad\left(\underline{b}-p_{1}\right)^{1-\rho}-\sum_{i=1}^{m(\underline{b})} \alpha_{i}\left(\underline{b}-x_{i}\right)^{1-\rho}=0 \\
& 0 \leq x_{1}<x_{2}<\ldots<x_{m(\underline{b})}<\underline{b} \\
& \alpha_{1}, \alpha_{2}, \ldots \ldots, \alpha_{m(\underline{b})}>0
\end{aligned}
$$

With $\lambda_{0}$ and $\lambda_{1}$ as Lagrange multipliers, we write:

$$
\begin{aligned}
& L\left(\left\{p_{2,1}, p_{2,2}, \ldots, p_{2, j(b)}\right\},\left\{\alpha_{1}, \alpha_{2}, \ldots . ., \alpha_{j(b)}\right\}, \lambda_{0}, \lambda_{1}\right)= \\
& \sum_{i=1}^{m(b)} \alpha_{i}\left(b-p_{2, i}\right) p_{2, i}+\lambda_{0}\left(1-\sum_{i=1}^{m(b)} \alpha_{i}\right) \\
& +\lambda_{1}\left(\left(b-p_{1}\right)^{1-\rho}-\sum_{i=1}^{m(b)} \alpha_{i}\left(b-p_{2, i}\right)^{1-\rho}\right)
\end{aligned}
$$

We are interested in the following two necessary conditions

$$
\begin{aligned}
& \frac{\partial L(\cdot)}{\partial x_{i}}=\alpha_{i}\left(b-2 x_{i}\right)+\lambda_{1} \alpha_{i}(1-\rho)\left(b-x_{i}\right)^{-\rho}=0 \\
& \frac{\partial L(\cdot)}{\partial \alpha_{i}}=\left(b-x_{i}\right) x_{i}-\lambda_{0}-\lambda_{1}\left(b-x_{i}\right)^{1-\rho}=0 \\
& i=1,2, \ldots, m(b)
\end{aligned}
$$

By the strict concavity of the utility function we have

$$
\begin{gathered}
\left(b-p_{1}\right)^{1-\rho}-\sum_{i=1}^{m(b)} \alpha_{i}\left(b-x_{i}\right)^{1-\rho}> \\
\left(b-p_{1}\right)^{1-\rho}-\left(b \sum_{i=1}^{m(b} \alpha_{i}-\sum_{i=1}^{m(b)} \alpha_{i} x_{i}\right)^{1-\rho}
\end{gathered}
$$

And by Lemma $1, p_{1}>\sum_{i=1}^{m(b)} \alpha_{i} x_{i}$. Therefore, $\sum_{i=1}^{m(b)} \alpha_{i}<1$ and $\lambda_{0}=0$

Next, we assume without any loss of generality, that the probabilities variables $\left\{\alpha_{i}\right\}$ are all non zero. Alternatively, if any of the probabilities were zero we could just drop the corresponding price variable and deal with the form $S_{n-1}$; we would then consummately require $n-1>2$.

We get by (22) and (23)

$$
\begin{aligned}
& \lambda_{1}=\frac{2 x_{i}-\underline{b}}{(1-\rho)\left(\underline{b}-x_{i}\right)^{-\rho}}=\frac{x_{j}}{\left(\underline{b}-x_{j}\right)^{-\rho}} \\
& \forall i, j=1,2, \ldots, m(\underline{b})
\end{aligned}
$$

However, this condition may possibly be satisfied by exactly two prices: $\frac{\underline{b}}{1+\rho}$, and $\underline{b}$. In order to see that, consider the following two functions

$$
\begin{aligned}
& f_{1}(x)=\frac{2 x-\underline{b}}{(1-\rho)(\underline{b}-x)^{-\rho}} \\
& f_{2}(x)=\frac{x}{(\underline{b}-x)^{-\rho}}
\end{aligned}
$$

Now, we let $y=\frac{\underline{b}}{1+\rho}+d$, where $\mathrm{d}$ is a constant. We evaluate the difference at this point

$$
f_{1}(y)-f_{2}(y)=d\left(\underline{b}-\frac{\underline{b}}{1+\rho}-d\right)(b \rho-d(\rho+1))
$$

When $y<\underline{b}$ both terms in brackets are strictly positive and the two functions intersect if and only if $\mathrm{d}=0$. When $y \rightarrow \underline{b}$, both functions approach zero and the difference between them becomes arbitrarily small.

Finally, the above consists a contradiction to the optimality of the policy $S_{n}$ with any $\mathrm{n}>2$ and we conclude that the optimal policy with risk aversion entails charging exactly two prices. 